\title{
Effects of Lung Distension and Spontaneous Fetal Breathing on Hemodynamics in Sheep
}

\author{
HARRIET S. IWAMOTO, DAVID F. TEITEL, AND ABRAHAM M. RUDOLPH \\ Cardiovascular Research Institute and the Departments of Pediatrics, Physiology, and Obstetrics, Gynecology, \\ and Reproductive Sciences, University of California, San Francisco, California 94143-0544
}

\begin{abstract}
In previous studies, we determined that pulmonary ventilation and oxygenation were largely responsible for increasing pulmonary blood flow and for altering central blood flow patterns but could not account for the increase in combined ventricular output (the sum of left and right ventricular outputs) that usually occurs after birth. We had ventilated fetuses with oscillating positive pressures; the possibility that high intrathoracic pressures adversely affected cardiac output could not be ruled out. To determine the effects of negative intrathoracic pressure ventilation, we occluded the umbilical cord of nine longterm instrumented fetal sheep at $135 \pm 1.2 \mathrm{~d}$ gestation while introducing humidified oxygen gas intratracheally. This stimulated continuous fetal respiratory activity, which resulted in negative intrathoracic pressures and increased fetal oxygenation. Pulmonary blood flow increased from $121 \pm 60$ to $901 \pm 139 \mathrm{~mL} \cdot \min ^{-1} \cdot 100 \mathrm{~g}^{-1}($ mean $\pm \mathrm{SD})$ and descending aortic blood pressure increased from 7.0 \pm 1.2 to $9.6 \pm 2.0 \mathrm{kPa}$. Central blood flow patterns were altered so that right to left shunting of blood through the foramen ovale and ductus arteriosus was abolished and a left to right shunt developed across the ductus arteriosus. However, cardiac output did not increase significantly. This may be related, in part, to the increase in afterload. It is clear that pulmonary ventilation and oxygenation are the major factors responsible for changing pulmonary blood flow and central blood flow patterns at birth. Other birthrelated events, such as a decrease in environmental temperature and an increase in metabolic rate, are likely to induce cardiac output to increase. (Pediatr Res 33: 639. 644, 1993)
\end{abstract}

At birth, the transfer of the site of gas exchange from the placenta to the lungs is one event that has a major influence on circulatory dynamics. With the onset of pulmonary ventilation, pulmonary vascular resistance falls and pulmonary blood flow increases. The vascular shunts present in the fetal circulation, the ductus venosus, foramen ovale, and ductus arteriosus, close functionally shortly after birth and a series arrangement of the circulation is established. We and others have shown previously that initiation of rhythmic pulmonary ventilation and oxygenation are events that are largely responsible for these changes in central and peripheral blood flow patterns (1-4). However, neither birth-related event was associated with a large increase in combined ventricular output that normally occurs at birth. In those studies, we applied positive pressure to ventilate fetal sheep. Because positive pressure ventilation in postnatal animals has

Received September 23, 1992; accepted January 26, 1993.

Correspondence: Harriet S. Iwamoto, Ph.D., Department of Pediatrics, Division of Neonatology/TCHRF Division, Children's Hospital Medical Center, Elland and Bethesda Aves., Cincinnati, OH 45229-2899.

Supported by NIH Research Grant HL 35842. been shown to have independent effects on blood flow, neural reflexes, and hormone responses in proportion to the inflation pressures achieved $(5,6)$, the possibility exists that some of the responses observed previously were a consequence of positive pressure ventilation per se, and not related to normal breathing activity initiated at birth.

Recent studies have demonstrated that spontaneous negative pressure pulmonary ventilation can be initiated and maintained in fetal sheep when the umbilical cord is occluded while oxygen is introduced into the fetal trachea $(7-10)$. We applied this technique to determine the effects of spontaneous, rhythmic pulmonary ventilation on blood flow patterns at birth. We measured combined ventricular output, the sum of left and right ventricular outputs, and peripheral blood flow distribution in a group of fetal sheep in utero to determine the effects of spontaneous negative pressure ventilation on hemodynamics at birth.

\section{MATERIALS AND METHODS}

Animals and Surgical Preparation. All procedures complied with NIH guidelines and were approved by the Committee on Animal Research at UCSF. We studied nine fetal sheep at $135 \pm 1.2 \mathrm{~d}$ gestational age (range $133-137 \mathrm{~d}$; term is $145 \mathrm{~d}$ ). Food, but not water, was withheld from the ewe for 24-36 h before surgery. After local anesthesia (2\% lidocaine hydrochloride), low spinal or epidural anesthesia was achieved with $4 \mathrm{~mL}$ of $1 \%$ tetracaine hydrochloride (Pontocaine $\mathrm{HCl}$, Breon Laboratories, New York, NY). Polyvinyl catheters (1.3 mm inner diameter, $2.3 \mathrm{~mm}$ outer diameter) were placed into the descending aorta and inferior vena cava of the ewe via a pedal artery and vein. The ewe received a continuous infusion of $0.9 \% \mathrm{NaCl}$, and $50-100 \mathrm{mg}$ of ketamine hydrochloride (Vetalar, ParkeDavis, Morris Plains, $\mathrm{NJ}$ ) was administered at 15 -min intervals throughout the duration of the surgical procedure. Local anesthetic, 2 or $0.25 \%$ lidocaine hydrochloride, was applied before each maternal or fetal skin incision, respectively.

The pregnant horn of the uterus was exposed through a midline incision in the abdomen of the ewe. Polyvinyl catheters $(0.75$ $\mathrm{mm}$ inner diameter, $1.2 \mathrm{~mm}$ outer diameter) were inserted into fetal hindlimb vessels and advanced so their tips were located in the descending aorta and inferior vena cava. Two polyvinyl catheters $(3.5 \mathrm{~F})$ were advanced into a main umbilical vein from peripheral tributaries, and one catheter was placed in the amniotic cavity. The fetal skin and uterine incisions were sutured.

For the remainder of the surgery, ketamine was injected i.v. into the fetus $(5 \mathrm{mg} / \mathrm{kg}$ ) every $15 \mathrm{~min}$. Through a second hysterotomy and a thoracotomy in the third intercostal space of the fetus, polyvinyl catheters were placed in the ascending aorta from the internal thoracic artery, in the superior vena cava from the external jugular vein, and directly into the left atrium, pulmonary artery, and pleural cavity. A $4.5-\mathrm{mm}$ endotracheal tube, connected by a $Y$-tube to two $100-\mathrm{cm}$ lengths of flexible polyvinyl tubing (3.2 $\mathrm{mm}$ inner diameter, $6.4 \mathrm{~mm}$ outer diameter), was filled with $0.9 \%$ saline and inserted into the fetal trachea. An 
inflatable silicone rubber cuff, which did not constrict the umbilical vessels when deflated, was placed around the umbilical cord at the umbilical ring. All incisions were sutured and the vascular catheters were filled with heparin sodium solution ( 1000 $\mathrm{U} / \mathrm{mL}$ ) and sealed. All catheters and ventilation tubing were exteriorized to the maternal flank and protected by a cloth pouch. A catheter in the amniotic cavity was connected to the ventilation tubing to allow tracheal fluid to flow freely from the fetus to the amniotic cavity postoperatively. Antibiotics ( $400 \mathrm{mg}$ of kanamycin, 1 million $U$ of penicillin) were instilled into the amniotic cavity and injected into the maternal vein on the day of surgery and each day thereafter. The animals were allowed 2 to $3 \mathrm{~d}$ to recover from surgery.

Experimental Procedure. On the day of the study, the ewes were placed in a mobile cart and allowed to become accustomed to laboratory surroundings for at least $2 \mathrm{~h}$. Food and water were provided. Fetal blood pressures and heart rate were monitored continuously throughout the experimental period (Statham P23Db strain-gauge transducers and Gould 2800S polygraph, Gould Inc., Cleveland, OH). Measurements were made in the fetuses under four conditions.

Control. Fetal pressures and heart rate were recorded for 30 $45 \mathrm{~min}$. Blood samples were obtained from the descending aorta for the determination of $\mathrm{pH}, \mathrm{PO}_{2}, \mathrm{PCO}_{2}$, and glucose and lactate concentrations, and from the ascending and descending aorta, pulmonary artery, umbilical vein, left atrium, and inferior vena cava for the determination of $\mathrm{Hb}$ concentration, blood oxygen saturation, and blood glucose and lactate concentrations (model 158 blood gas analyzer, Corning Medical, Medfield, MA; model OSM2 Hemoximeter, Radiometer, Copenhagen, Denmark; models $23 \mathrm{~A}$ and $23 \mathrm{~L}$ glucose and lactate analyzers, Yellow Springs Instrument Co., Yellow Springs, OH). Arterial plasma samples were obtained and stored until they were analyzed for catecholamine concentration (11). Combined ventricular output and blood flow distribution were then determined by injecting two differently labeled $15-\mu \mathrm{m}$ microspheres (selected from ${ }^{57} \mathrm{Co}$, ${ }^{51} \mathrm{Cr},{ }^{153} \mathrm{Gd},{ }^{114} \mathrm{In},{ }^{54} \mathrm{Mn},{ }^{95} \mathrm{Nb},{ }^{113} \mathrm{Sn},{ }^{85} \mathrm{Sr}$, and ${ }^{65} \mathrm{Zn}$; New England Nuclear, Boston, MA) into the inferior vena cava and left atrium while obtaining reference samples at a rate of $3.88 \mathrm{~mL} / \mathrm{min}$ from the descending and ascending aorta and the pulmonary artery. The volume of blood removed for the blood and reference samples was replaced simultaneously with an equal volume of fetal donor or, in rare instances, maternal blood. After the control period, Exosurf (obtained from Burroughs Wellcome Co., Research Triangle Park, NC, or Dr. John Clements, UCSF) was instilled in the tracheal tubing and flushed back and forth to ensure delivery of the surface active material to alveolar surfaces. After the control measurements were made, the two polyvinyl tubes connected to the endotracheal tube were opened to the atmosphere and allowed to drain. Then, the procedures detailed below were performed in random order.

Inflation of lungs with fetal gas mixture (distension). We prepared a mixture of oxygen, carbon dioxide, and nitrogen gases that matched fetal blood gases during the control period (approximately $3 \% \mathrm{O}_{2}, 5 \% \mathrm{CO}_{2}$, and $92 \% \mathrm{~N}_{2}$ ). To expand the fetal lungs, this mixture was humidified and introduced into one of the polyvinyl tubes at a rate of $1-2 \mathrm{~L} / \mathrm{min}$ and a positive pressure of approximately 7-10 $\mathrm{cm} \mathrm{H}_{2} \mathrm{O}$. After $15-20$ min elapsed and fetal pressures were stable, measurements were made as during the control period.

Inflation of lungs with oxygen (oxygenation). One hundred percent oxygen gas was humidified and introduced into the tracheal tubing at a rate of $1-2 \mathrm{~L} / \mathrm{min}$ and a positive pressure of $7-10 \mathrm{~cm} \mathrm{H}_{2} \mathrm{O}$. Expansion of the lungs was ensured by evidence of increased oxygen saturation and tension in fetal blood. After 15-20 min elapsed and fetal pressures were stable, measurements were made as during the control period.

Spontaneous fetal breathing (breathing). The umbilical cord was completely occluded while $100 \% \mathrm{O}_{2}$ flowed through the tracheal tubing. An average of 1-5 min elapsed before the fetus first gasped, then initiated continuous breathing. Effective pulmonary ventilation was assessed by a marked increase in arterial oxygenation. When arterial oxygen tension stabilized, after approximately 15-20 min, measurements were made as during the control period. Not all fetuses were studied under all four conditions. Thus, we report results of nine control, five distension, nine oxygenation, and eight breathing studies conducted in random order.

Upon completion of the last set of measurements, the ewe was killed with an i.v. injection of 6-10 g of sodium pentobarbital and bilateral thoracotomy. The uterus and individual fetal organs were dissected, weighed, and placed in formalin. Organs were carbonized in an oven at $350^{\circ} \mathrm{C}$, ground into a coarse powder, placed into plastic vials to a uniform height of $3 \mathrm{~cm}$, and counted in a 1000-channel multichannel pulse-height analyzer (Norland Corp., Fort Atkinson, WI). The activity of each isotope in each organ was determined by the least-squares method described previously (12).

Data Analysis. Blood flow to fetal organs was calculated in the control period by comparing the radioactivity of the microsphere injected into the inferior vena cava in each organ with the radioactivity and flow rate of the appropriate reference sample (ascending aorta for upper body organs and descending aorta for lower body organs), as described previously in detail (13). After the fetuses were ventilated, pulmonary blood flow and blood flow through vascular shunts characteristic of the fetal circulation were altered dramatically (2). Therefore, for distension, oxygenation, and breathing measurements, blood flow to fetal organs was calculated using the radioactivity of the microspheres injected into the left atrium (2).

Data were analyzed by one-way analysis of variance. Significant differences between mean values were determined by Dunnett's $t$ test. All data are expressed as mean $\pm \mathrm{SD}$, and actual $p$ values are indicated.

\section{RESULTS}

The fetuses weighed an average of $3.23 \pm 0.66 \mathrm{~kg}$. Fetal arterial blood $\mathrm{pH}$, gases, oxygen content, glucose, and lactate and plasma catecholamine concentrations were initially within the normal range (Table 1). When fetal lungs were distended with a mixture of $3 \% \mathrm{O}_{2}, 5 \% \mathrm{CO}_{2}$, and $92 \% \mathrm{~N}_{2}$ applied with a positive pressure of $11 \pm 6$ torr (distension), these variables did not change significantly. When fetal lungs were distended with $100 \%$ oxygen (oxygenation), oxygen content in the aorta, left atrium, and inferior vena cava increased significantly over control values. When the umbilical cord was occluded while the lungs were distended with oxygen, continuous fetal breathing began within 1-5 min. At the time of the first fetal gasp, arterial $\mathrm{pH}$ and $\mathrm{PCO}_{2}$ were $7.04 \pm 0.07$ and $14.5 \pm 1.2 \mathrm{kPa}$, respectively. After $10-15$ min of continuous fetal breathing, arterial $\mathrm{pH}$ and $\mathrm{PCO}_{2}$ were $7.03 \pm 0.11$ and $15.4 \pm 4.0 \mathrm{kPa}$, respectively (Table 1). Arterial $\mathrm{PO}_{2}$ and oxygen content in the aorta, pulmonary artery, and left atrium increased. Plasma concentrations of norepinephrine and epinephrine increased and dopamine decreased during fetal breathing (Table 1).

Fetal heart rate and blood pressures were initially within range of normal values (Table 2). Distension or oxygenation had no significant effects on these values. Spontaneous fetal breathing increased aortic and left atrial pressures but did not change heart rate significantly (Table 2 ).

Combined ventricular output was $365 \pm 107 \mathrm{~mL} \cdot \mathrm{min}^{-1} \cdot \mathrm{kg}^{-1}$ initially and did not change significantly with distension, oxygenation, or fetal breathing (Table 3). During the control period, left ventricular output was significantly less than right ventricular output (Fig. 1). With distension and oxygenation, left ventricular output increased slightly and right ventricular output decreased slightly so that they were not significantly different from each other. During fetal breathing, left ventricular output was significantly greater than right ventricular output $(p<0.02)$. Although 
Table 1. Effect of birth-related events on constituents of fetal blood*

\begin{tabular}{|c|c|c|c|c|}
\hline & Control & Distension & Oxygenation & Breathing \\
\hline Descending aorta $(n)$ & 9 & 5 & 9 & 8 \\
\hline $\mathrm{pH}$ & $7.37 \pm 0.02$ & $7.35 \pm 0.03$ & $7.29 \pm 0.12$ & $7.03 \pm 0.11 \dagger$ \\
\hline $\mathrm{PCO}_{2}(\mathrm{kPa})$ & $7.2 \pm 0.4$ & $7.3 \pm 0.5$ & $7.8 \pm 0.9$ & $15.4 \pm 4.0 \dagger$ \\
\hline $\mathrm{PO}_{2}(\mathrm{kPa})$ & $2.3 \pm 0.4$ & $2.8 \pm 0.3$ & $5.3 \pm 3.7$ & $20.0 \pm 10.8 \dagger t$ \\
\hline Glucose (mM) & $0.94 \pm 0.28$ & $1.09 \pm 0.37$ & $1.46 \pm 1.18$ & $1.84 \pm 1.32$ \\
\hline Lactate $(\mathrm{mM})$ & $2.95 \pm 2.66$ & $2.26 \pm 1.36$ & $3.70 \pm 3.12$ & $2.80 \pm 1.68$ \\
\hline Norepinephrine & $1219 \pm 537$ & $896 \pm 347$ & $881 \pm 543$ & $2869 \pm 2252 \S 月 \pi$ \\
\hline Epinephrine & $112 \pm 108$ & $113 \pm 78$ & $140 \pm 169$ & $3917 \pm 3927 \dagger \neq \pi$ \\
\hline Dopamine & $102 \pm 51$ & $62 \pm 14$ & $55 \pm 11 \S$ & $62 \pm 22 \S$ \\
\hline \multicolumn{5}{|l|}{ Oxygen content (mM) } \\
\hline Descending aorta & $2.48 \pm 0.98$ & $2.99 \pm 0.93$ & $4.52 \pm 0.94 \dagger+$ & $5.67 \pm 1.23 \dagger \neq \|$ \\
\hline Ascending aorta & $3.01 \pm 1.03$ & $2.95 \pm 0.87$ & $4.57 \pm 1.27 \dagger \|$ & $5.73 \pm 1.22 \dagger \ddagger$ \\
\hline Pulmonary artery & $2.59 \pm 0.90$ & $2.82 \pm 0.91$ & $3.74 \pm 1.19$ & $4.63 \pm 1.77 \S \|$ \\
\hline Left atrium & $2.94 \pm 1.20$ & $3.00 \pm 1.16$ & $4.29 \pm 1.17 \S$ & $5.59 \pm 1.16 \dagger \ddagger$ \\
\hline Umbilical vein & $4.32 \pm 0.77$ & $4.31 \pm 1.14$ & $5.17 \pm 1.12$ & Not determined \\
\hline Inferior vena cava & $1.52 \pm 0.77$ & $1.65 \pm 0.71$ & $2.89 \pm 1.64 \S$ & $3.94 \pm 0.97 \dagger \ddagger$ \\
\hline
\end{tabular}

* Norepinephrine, epinephrine, and dopamine are plasma concentrations in pg/mL. Data are expressed as mean \pm SD and were analyzed by oneway analysis of variance and Dunnett's $t$ test. Significant differences between means are indicated by footnote symbols.

$\dagger$ Different from control, $p<0.01$.

$\ddagger$ Different from distension, $p<0.01$.

$\S$ Different from control, $p<0.05$.

$\|$ Different from distension, $p<0.05$.

I Different from oxygenation, $p<0.05$.

Table 2. Effect of birth-related events on fetal heart rate and vascular pressures*

\begin{tabular}{lcccc}
\hline & Control & Distension & Oxygenation & Breathing \\
\hline Heart rate & $191 \pm 6$ & $182 \pm 30$ & $194 \pm 37$ & $180 \pm 46$ \\
Mean blood pressure $(\mathrm{kPa})$ & & & & \\
$\quad$ Descending aorta & $7.0 \pm 1.2$ & $6.8 \pm 1.2$ & $6.9 \pm 0.9$ & $9.6 \pm 2.0+ \pm \S$ \\
Ascending aorta & $6.8 \pm 1.1$ & $6.7 \pm 0.8$ & $6.7 \pm 0.9$ & $8.6 \pm 2.0 \dagger \| \uparrow$ \\
Pulmonary artery & $7.3 \pm 1.1$ & $6.7 \pm 1.2$ & $7.0 \pm 0.9$ & $8.2 \pm 2.4$ \\
Left atrium & $0.5 \pm 0.4$ & $0.7 \pm 0.1$ & $0.5 \pm 0.8$ & $1.3 \pm 0.5 \| \boldsymbol{\pi *}$ \\
Umbilical vein & $1.6 \pm 0.8$ & $1.1 \pm 0.5$ & $1.6 \pm 0.7$ & Not determined \\
Inferior vena cava & $0.5 \pm 0.7$ & $0.7 \pm 0.5$ & $0.8 \pm 0.7$ & $0.7 \pm 0.5$ \\
\hline
\end{tabular}

* All pressures are corrected to amniotic cavity pressure as zero reference. Data are expressed as mean \pm SD. Data were analyzed by one-way analysis of variance and Dunnett's $t$ test. Significant differences between means are indicated by footnote symbols.

$\dagger$ Different from control, $p<0.01$.

$\ddagger$ Different from distension, $p<0.01$.

$\S$ Different from oxygenation, $p<0.01$.

$\|$ Different from distension, $p<0.05$.

I Different from oxygenation, $p<0.05$.

** Different from control, $p<0.05$.

combined ventricular output increased slightly with distension, oxygenation, and breathing, the changes were not significantly different from control values.

During the control period, there was normal fetal right to left shunting of blood across the foramen ovale and ductus arteriosus at rates of $144 \pm 87$ and $200 \pm 53 \mathrm{~mL} \cdot \mathrm{min}^{-1} \cdot \mathrm{kg}^{-1}$, respectively, and no detectable left to right shunt across the ductus arteriosus (Fig. 2). During distension, the magnitude of the right to left shunt across the ductus arteriosus decreased significantly. During oxygenation, the magnitude of the right to left shunts across the foramen ovale and ductus arteriosus were decreased relative to control values and a small left to right shunt across the ductus arteriosus was detectable. During continuous fetal breathing, the right to left shunts across the foramen ovale and ductus arteriosus were markedly reduced relative to control and there was a large left to right shunt across the ductus arteriosus.

Blood flow to the placental circulation was stable until the umbilical cord was occluded to initiate continuous fetal breathing (Tables 3 and 4). Blood flow to the lungs increased slightly with lung inflation; a significant increase was observed only when the lungs were inflated with oxygen. Continuous fetal breathing increased lung blood flow markedly to over $50 \%$ of total combined ventricular output (Table 4), which is compatible with the abolition of the right to left shunt and the initiation of a left to right shunt across the ductus arteriosus. Regression analysis of pulmonary blood flow and arterial $\mathrm{pH}, \mathrm{PO}_{2}$, and $\mathrm{PCO}_{2}$ during oxygenation and breathing revealed close relationships between pulmonary blood flow and arterial $\mathrm{PO}_{2}$ [blood flow $=330+(9.6$. $\left.\mathrm{PO}_{2}\right)-\left(0.04 \cdot \mathrm{PO}_{2}{ }^{2}\right) ; r^{2}=0.51, p<0.03$ ] and arterial $\mathrm{PCO}_{2}$ [blood flow $\left.=-67+\left(14 \cdot \mathrm{PCO}_{2}\right)-\left(0.05 \cdot \mathrm{PCO}_{2}{ }^{2}\right) ; r^{2}=0.49, p<0.04\right]$. Blood flow to the fetal diaphragm was measured in four fetuses and was $19 \pm 8 \mathrm{~mL} \cdot \mathrm{min}^{-1} \cdot 100 \mathrm{~g}^{-1}$ during control. Lung inflation had no effect on diaphragm blood flow, but continuous fetal breathing increased it to $47 \pm 12 \mathrm{~mL} \cdot \mathrm{min}^{-1} \cdot 100 \mathrm{~g}^{-1}$ (greater than control, distension, and oxygen values, $p<0.05$ ). Blood flow to the fetal brain increased significantly during fetal breathing to twice the control value, but this was probably secondary to the respiratory acidosis produced rather than an effect of breathing alone. Stepwise regression analysis of cerebral blood flow and arterial $\mathrm{pH}, \mathrm{PO}_{2}, \mathrm{PCO}_{2}$, and oxygen content during oxygenation and breathing revealed close relationships between cerebral blood flow and arterial $\mathrm{pH}$ [blood flow $=0.00048$ $\left.(12794 \cdot \mathrm{pH})+\left(850 \cdot \mathrm{pH}^{2}\right) ; r^{2}=0.86, p<0.0001\right]$ and between cerebral blood flow and arterial $\mathrm{PCO}_{2}$ [blood flow $=-70+(2.98$. $\left.\left.\mathrm{PCO}_{2}\right) ; r^{2}=0.78, p<0.0001\right]$. Blood flow to the liver via the hepatic artery and the proportion of total flow to the liver and 
Table 3. Effects of birth-related events on blood flow in fetal sheep*

\begin{tabular}{lcccc}
\hline & Control & Distension & Oxygenation & Breathing \\
\hline$n$ & 9 & 5 & 8 & 7 \\
Combined ventricular output & $365 \pm 107$ & $422 \pm 111$ & $442 \pm 106$ & $435 \pm 134$ \\
Placenta & $138 \pm 50$ & $145 \pm 56$ & $129 \pm 27$ & $5 \pm 10 \dagger \ddagger \S$ \\
Adrenal & $265 \pm 192$ & $257 \pm 163$ & $173 \pm 83$ & $343 \pm 227$ \\
Spleen & $231 \pm 136$ & $341 \pm 313$ & $402 \pm 368$ & $437 \pm 505$ \\
Gut & $90 \pm 47$ & $76 \pm 36$ & $46 \pm 24$ & $57 \pm 41$ \\
Liver & $6.8 \pm 7.9$ & $5.0 \pm 4.8$ & $9.1 \pm 11.6$ & $32 \pm 23 \dagger \ddagger \S$ \\
Kidney & $209 \pm 83$ & $155 \pm 40$ & $167 \pm 65$ & $137 \pm 89$ \\
Brain & $149 \pm 80$ & $135 \pm 31$ & $94 \pm 38$ & $298 \pm 103 \dagger \ddagger \S$ \\
Thyroid & $129 \pm 108$ & $90 \pm 41$ & $114 \pm 166$ & $68 \pm 72$ \\
Myocardium & $249 \pm 177$ & $271 \pm 124$ & $164 \pm 80$ & $11 \pm \pm 58$ \\
Periphery & $16 \pm 7$ & $13 \pm 4$ & $11 \pm 5$ \\
Lungs & $121 \pm 60$ & $281 \pm 219$ & $629 \pm 277 \dagger \|$ & $901 \pm 139 \dagger \ddagger \uparrow$ \\
\hline
\end{tabular}

* Liver represents the hepatic arterial contribution only; periphery represents the skin, muscle, and bone. Blood flow is expressed in $\mathrm{mL} \cdot \mathrm{min}^{-1}$. $\mathrm{kg}^{-1}$ for combined ventricular output and placental blood flow; all other flows are in $\mathrm{mL} \cdot \mathrm{min}^{-1} \cdot 100 \mathrm{~g}^{-1}$. Data are expressed as mean $\pm \mathrm{SD}$. Significant differences between means are indicated by footnote symbols.

$\dagger$ Different from control, $p<0.01$.

$¥$ Different from distension, $p<0.01$.

$\S$ Different from oxygenation, $p<0.01$.

$\|$ Different from distension, $p<0.05$.

I Different from oxygenation, $p<0.05$.

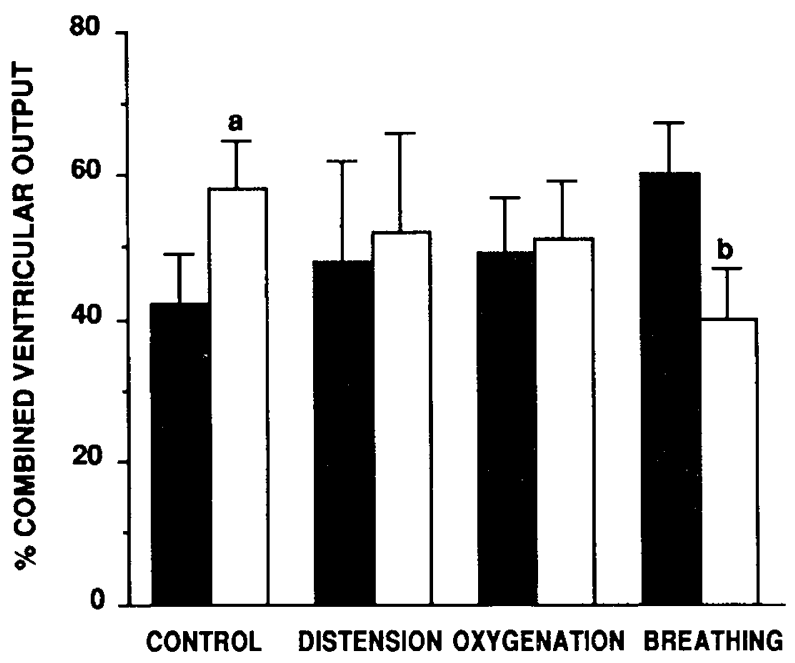

Fig. 1. Effect of fetal lung distension with nitrogen or oxygen and of spontaneous rhythmic breathing on left (solid bars) and right (open bars) ventricular outputs. Data are expressed as a percentage of combined ventricular output + SD. During control and breathing periods, right ventricular output was significantly greater $(a, p<0.05)$ and less than $(b, p<0.02)$ left ventricular output by paired $t$ test. However, there were no significant changes in either left or right ventricular outputs throughout the course of the experiments.

gastrointestinal tract increased significantly during continuous fetal breathing (Tables 3 and 4). The proportion of combined ventricular output distributed to the peripheral circulation decreased slightly during fetal breathing, and there were no other changes in organ blood flow (Table 4).

\section{DISCUSSION}

Previous studies using positive pressure ventilation and oxygenation in fetal sheep have demonstrated that these components of the birth process are sufficient to effect changes in central and regional blood flow patterns normally seen at birth (1-4) but are not sufficient to increase combined ventricular output. To determine whether the absence of an increase in combined ventricular output was related to the use of positive pressures to ventilate fetuses, we studied the effects of spontaneous fetal breathing induced by umbilical cord occlusion $(7-10)$. Distension of fetal

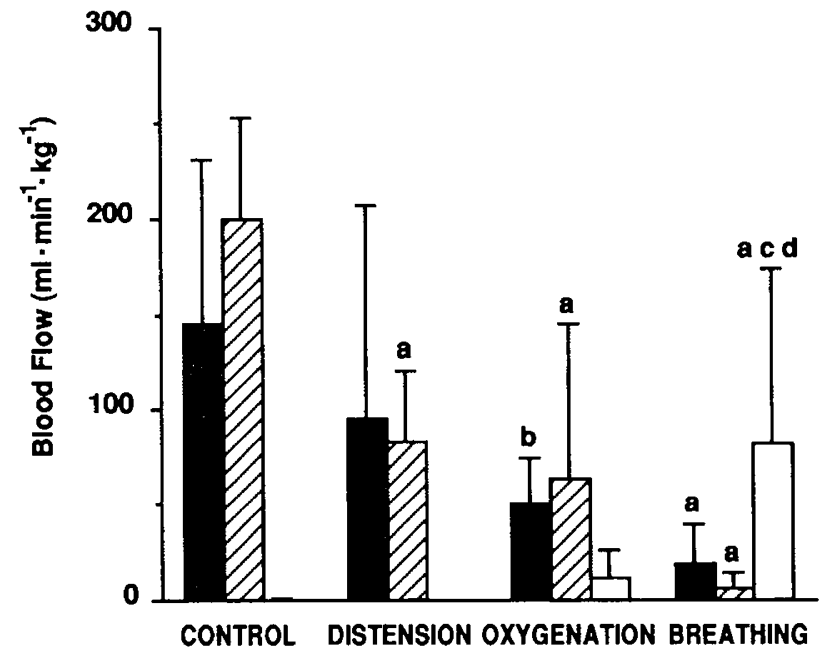

Fig. 2. Effect of fetal lung distension with nitrogen or oxygen and of spontaneous rhythmic breathing on blood flow shunts in the fetal circulation. The solid bars represent blood flow ihrough the foramen ovale from the right to left atrium, the hatched bars represent blood flow through the ductus arteriosus from the pulmonary trunk to the descending aorta (right to left), and the open bars represent blood flow through the ductus arteriosus from the descending aorta to the pulmonary trunk (left to right). Data are shown as means $+\mathrm{SD}$. Distension of fetal lungs with nitrogen gas significantly decreased the magnitude of the right to left shunt across the ductus arteriosus relative to control $(a, p<0.01)$. Distension of fetal lungs with oxygen and oxygenation decreased the magnitude of the right to left shunt across the foramen ovale relative to control $(b, p<0.05)$. Spontaneous, rhythmic fetal breathing was associated with significantly reduced right to left shunts across the foramen ovale and ductus arteriosus. A significant left to right shunt across the ductus arteriosus that was greater than control, distension $(c, p<0.05)$, and oxygenation $(d, p<0.05)$ values was evident during breathing.

lungs in utero with nitrogen produced no significant changes in fetal blood pressures or blood flows. Lung distension with oxygen increased blood oxygen content and pulmonary blood flow. When spontaneous fetal breathing was stimulated by occluding the umbilical cord while introducing oxygen gas to the fetal trachea (7), major hemodynamic changes were observed. Mean blood pressures in the aorta and left atrium increased, pulmonary vascular resistance decreased, pulmonary blood flow increased, 
Table 4. Effect of birth-related events on distribution of combined ventricular output in fetal sheep*

\begin{tabular}{|c|c|c|c|c|}
\hline & Control & Distension & Oxygenation & Breathing \\
\hline$n$ & 8 & 5 & 7 & 6 \\
\hline Placenta & $39 \pm 10$ & $31 \pm 9$ & $30 \pm 9$ & $1 \pm 2+\ddagger \S$ \\
\hline Adrenal & $0.10 \pm 0.06$ & $0.08 \pm 0.03$ & $0.06 \pm 0.03$ & $0.12 \pm 0.05$ \\
\hline Spleen & $0.75 \pm 0.27$ & $0.80 \pm 0.46$ & $1.15 \pm 0.84$ & $1.14 \pm 1.25$ \\
\hline Gut & $8.5 \pm 1.9$ & $5.7 \pm 2.3$ & $4.4 \pm 2.3$ & $5.4 \pm 3.0 \dagger \|$ \\
\hline Liver & $0.30 \pm 0.25$ & $0.29 \pm 0.27$ & $0.36 \pm 0.50$ & $1.67 \pm 1.10 \dagger \ddagger \S$ \\
\hline Kidney & $3.1 \pm 1.2$ & $1.9 \pm 0.4$ & $2.1 \pm 0.9$ & $1.7 \pm 1.3$ \\
\hline Brain & $5.8 \pm 2.4$ & $4.3 \pm 1.3$ & $3.3 \pm 1.0$ & $11.2 \pm 7.8 \S \| \boldsymbol{\Phi}$ \\
\hline Thyroid & $0.09 \pm 0.07$ & $0.06 \pm 0.03$ & $0.07 \pm 0.09$ & $0.05 \pm 0.05$ \\
\hline Myocardium & $3.2 \pm 1.8$ & $3.5 \pm 1.6$ & $2.0 \pm 0.6$ & $2.1 \pm 0.6$ \\
\hline Periphery & $29 \pm 5$ & $23 \pm 5$ & $19 \pm 8 \dagger$ & $19 \pm 6 \dagger$ \\
\hline Lungs & $8 \pm 2$ & $26 \pm 10$ & $37 \pm 15 t \ddagger$ & $56 \pm 8 \dagger \ddagger$ \\
\hline
\end{tabular}

* Liver represents the hepatic arterial contribution only; periphery represents the skin, muscle, and bone. Data are percentages expressed as mean \pm SD. Significant differences between means are indicated by footnote symbols.

$\dagger$ Different from control, $p<0.01$.

$\ddagger$ Different from distension, $p<0.01$.

$\S$ Different from oxygenation, $p<0.01$.

$\|$ Different from distension, $p<0.05$.

II Different from control, $p<0.05$.

the right to left shunting of blood across the foramen ovale and ductus arteriosus was abolished, and a left to right shunt across the ductus arteriosus became detectable.

In our previous study, we were unable to demonstrate an effect of mechanical pulmonary ventilation with nitrogen or with oxygen on combined ventricular output (1). We concluded that the events, pulmonary ventilation, oxygenation, and umbilical cord occlusion, could not account for the increase in combined ventricular output at birth. However, we could not rule out the possibility that the high intrathoracic pressures produced by positive-pressure ventilation adversely affected cardiac output. In the present study, spontaneous breathing was achieved by fetal inspiratory efforts that resulted in oscillating negative intrathoracic pressures and, still, combined ventricular output did not increase. There are several possible explanations for this. Although we have previously shown that in utero ventilation with oxygen may increase left ventricular output nearly 3 -fold, it does so only when the fetus is supplied with additional blood volume and heart rate is increased by isoproterenol infusion (14). In the present study, plasma catecholamines increased with fetal breathing, but probably not to concentrations comparable to the level of $\beta$-adrenergic receptor activation achieved by isoproterenol infusion. An increase in venous return was limited to the extent that the umbilical cord was occluded and a large volume of blood was retained in the placenta. Afterload increased in the present study and probably limited an increase in cardiac output to some extent. Changes in environmental temperature and metabolic rate at birth appear to be closely associated with the postnatal increase in cardiac output. Previous studies have shown that fetal thyroidectomy or adrenalectomy decrease the metabolic and hemodynamic responses to birth in parallel $(15,16)$. In the present study, the fetuses remained in utero, environmental temperature did not change, and it is unlikely that fetal metabolic rate increased to any significant degree. This might explain why we did not measure an increase in cardiac output in the present study.

Regardless of whether fetal lungs are ventilated mechanically with positive pressures $(2-4,17)$ or spontaneously with negative pressures (present study), initiation of pulmonary ventilation, particularly when accompanied by an increase in oxygenation, has significant effects on the blood flow through central shunts and pulmonary blood flow. As during positive-pressure ventilation, the magnitude of the right to left shunts across the foramen ovale and ductus arteriosus decreased and a left to right shunt developed during negative-pressure ventilation in this study. Pulmonary blood flow increased with distension of the lungs with oxygen, but the variability in blood flows was large-half the fetuses responded with a maximal increase (to $800-900 \mathrm{~mL}$. $\min \cdot \cdot^{-1} \cdot 100 \mathrm{~g}^{-1}$ ) and half had a somewhat smaller increase in blood flow (to $300-400 \mathrm{~mL} \cdot \mathrm{min} \cdot{ }^{-1} \cdot 100 \mathrm{~g}^{-1}$ ). The factors responsible for this variability are unknown, but the results are similar to those of our previous studies in which rhythmic pulmonary ventilation with no change in blood gases increased pulmonary blood flow maximally in half the fetuses studied. The factors responsible for the increase in pulmonary blood flow at birth have been explored recently by a number of investigators (18-21). Bradykinin, prostacyclin, and endothelium-derived relaxing factor are involved in reducing pulmonary vascular resistance at birth, but the exact mechanisms by which they are activated and exert their actions remain to be elucidated.

Cerebral blood flow varies inversely with arterial oxygen content, and cerebral blood flow decreases after birth as oxygen content increases (22). In previous studies, fetal oxygenation achieved by positive-pressure mechanical ventilation decreased cerebral blood flow to levels comparable to those observed in neonates $(1,3,23)$. In the present study, fetal breathing of $100 \%$ oxygen induced by umbilical cord compression increased arterial oxygen content and increased cerebral blood flow but also produced acidemia and hypercarbia. During fetal breathing, cerebral blood flow increased in direct relation to the increase in arterial carbon dioxide tension and hydrogen ion concentration. The sensitivity of fetal cerebral blood flow to carbon dioxide and $\mathrm{pH}$ has been described previously (24).

It is expected that the hypercarbia and acidemia produced by umbilical cord occlusion in the present study activated fetal chemoreflex activity (25-27). Chemoreceptors are quite well developed in the fetus, and chemoreceptor activation has profound effects on cardiovascular and endocrine systems $(26,28)$. The decrease in the proportion of blood flow distributed to the peripheral circulation (skin, muscle, and bone) and increases in plasma catecholamine concentrations and arterial blood pressure were likely consequences of chemoreceptor activation. Other cardiovascular responses known to be associated with chemoreceptor activation in the fetus, such as vasoconstriction in the renal and gastrointestinal vascular beds, did not occur. It is likely that any tendency for reflex neurohormonal mechanisms to increase vascular tone was counteracted by the local vasodilatory influences exerted by increases in the concentrations of carbon dioxide, hydrogen ion, and other vasodilatory substances.

Successful transition at birth from an intrauterine to extrauterine environment requires major hemodynamic and metabolic changes. In this and previous studies, we and others have demonstrated that rhythmic pulmonary ventilation has the primary effect of decreasing pulmonary vascular resistance and 
increasing pulmonary blood flow. As a consequence, the pattern of central blood flow changes from a parallel, fetal-type circuit to a series, postnatal circuit. This occurs when rhythmic breathing is achieved by positive or negative oscillations in intrathoracic pressures. Rhythmic pulmonary ventilation does not account for the increase in combined ventricular output normally seen after birth. Cardiac output is not increased during spontaneous oxygen breathing in the fetal sheep but is more likely increased at birth by neurohormonal stimulation and increases in venous return and metabolic rate.

\section{REFERENCES}

1. Iwamoto HS, Teitel D, Rudolph AM 1987 Effect of birth-related events on blood flow distribution. Pediatr Res 22:634-640

2. Teitel D, Iwamoto HS, Rudolph AM 1987 Effects of birth-related events on central blood flow patterns. Pediatr Res 22:557-566

3. Blanco CE, Martin CB, Rankin J, Landauer M, Phernetton T 1988 Changes in fetal organ flow during intrauterine mechanical ventilation with or without oxygen. J Dev Physiol 10:53-62

4. Reid DL, Thornburg KL 1990 Pulmonary pressure-flow relationships in the fetal lamb during in utero ventilation. J Appl Physiol 69:1630-1636

5. Daly MdB 1986 Interactions between respiration and circulation. In: Cherniack NS, Widdicombe JG (ed) Handbook of Physiology, Section 3: The Respiratory System, Vol II: Control of Breathing, Part I. American Physiological Society, Bethesda, MD, pp 529-594

6. Furzan JA, Babriele G, Wheeler JM, Fixler DE, Rosenfeld CR 1981 Regional blood flows in newborn lambs during endotracheal continuous airway pressure and continuous negative pressure breathing. Pediatr Res 15:874-878

7. Adamson SL, Richardson BS, Homan J 1987 Initiation of pulmonary gas exchange by fetal sheep in utero. J Appl Physiol 62:989-998

8. Baier RJ, Hasan SU, Cates DB, Hooper D, Nowaczyk B, Rigatto H 1990 Effects of various concentrations of $\mathrm{O}_{2}$ and umbilical cord occlusion on fetal breathing and behavior. J Appl Physiol 68:1597-1604

9. Hasan SU, Rigaux A 1991 The effects of lung distension, oxygenation, and gestational age on fetal behavior and breathing movements in sheep. Pediat Res 30:193-201

10. Hasan SU, Rigaux A 1992 Arterial oxygen tension threshold range for the onset of arousal and breathing in fetal sheep. Pediatr Res 32:342-349

11. Iwamoto HS, Kaufman T, Keil LC, Rudolph AM 1989 Responses to acute hypoxemia in fetal sheep at 0:6-0.7 gestation. Am J Physiol 256:H613-H620

12. Baer RW, Payne BA, Verrier ED, Vlahakes GJ, Molodowitch D, Uhlig PN, Hoffman JIE 1984 Increased number of myocardial blood flow measure- ments with radionuclide-labeled microspheres. Am J Physiol 246:H418$\mathrm{H} 434$

13. Heymann MA, Payne BD, Hoffman JIE, Rudolph AM 1977 Blood flow measurements with radionuclide-labeled particles. Prog Cardiovasc Dis 20:55-79

14. Teitel DF, Dalinghaus M, Cassidy SC, Payne BD, Rudolph AM 1991 In utero ventilation augments the left ventricular response to isoproterenol and volume loading in fetal sheep. Pediatr Res 29:466-472

15. Breall JA, Rudolph AM, Heymann MA 1984 Role of thyroid hormone in postnatal circulatory and metabolic adjustments. J Clin Invest 73:14181424

16. Padbury J, Agata X, Ludlow J, Ikegami M, Baylen B, Humme J 1987 Effect of fetal adrenalectomy on catecholamine release and physiologic adaptation at birth in sheep. J Clin Invest 80:1096-1103

17. Teitel DF, Iwamoto HS, Rudolph AM 1990 Changes in the pulmonary circulation during birth-related events. Pediatr Res 27:372-378

18. Abman SH, Chatfield BA, Hall SL, McMurtry IF 1990 Role of endotheliumderived relaxing factor during transition of pulmonary circulation at birth. Am J Physiol 259:H1921-H1927

19. Abman SH, Stenmark KR 1992 Changes in lung eicosanoid content during normal and abnormal transition in perinatal lambs. Am J Physiol 262:L214 L222

20. Shaul PW, Ferrar MA, Zellers TM 1992 Oxygen modulates endotheliumderived relaxing factor production in fetal pulmonary arteries. Am J Physiol 262:H355-H364

21. Fineman JR, Soifer SJ, Heymann MA 1991 The role of pulmonary vascular endothelium in perinatal pulmonary circulatory regulation. Semin Perinatol 15:58-62

22. Jones Jr MD, Sheldon RE, Peeters LL, Makowski EL, Meschia G 1978 Regulation of cerebral blood flow in the ovine fetus. Am J Physiol 235:H162H166

23. Gleason CA, Jones Jr MD, Traystman RJ, Notter RH 1988 Fetal cerebral responses to ventilation and oxygenation in utero. Am J Physiol 255:R1049R 1054

24. Rosenberg AA, Jones Jr MD, Traystman RJ, Simmons MA, Molteni RA 1982 Response of cerebral blood flow to changes in $\mathrm{PCO}_{2}$ in fetal, newborn, and adult sheep. Am J Physiol 242:H862-H866

25. Blanco CE, Dawes GS, Hanson MA, McCooke HB 1984 The response to hypoxia of arterial chemoreceptors in fetal sheep and new-born lambs. Physiol (Lond) 351:25-37

26. Hanson MA 1988 The importance of baro- and chemoreflexes in the control of the fetal cardiovascular system. J Dev Physiol 10:491-511

27. Walker DW 1984 Peripheral and central chemoreceptors in the fetus and newborn. Annu Rev Physiol 46:687-703

28. Itskovitz J, LaGamma EF, Bristow J Rudolph AM 1991 Cardiovascular responses to hypoxemia in sinoaortic-denervated fetal sheep. Pediatr Res $30: 381-385$ 